\title{
Characterization of lightweight concrete made of palm oil clinker aggregates
}

\author{
Muhammad Sazlly Nazreen ${ }^{1 *}$, Roslli Noor Mohamed ${ }^{2}$, Mariyana Aida Ab Kadir², Nazry \\ Azillah', Nazirah Ahmad Shukri', Shariwati Mansor ${ }^{1}$ and Fazlin Zamri ${ }^{1}$ \\ ${ }^{1}$ Postgraduate Student, Faculty of Civil Engineering, Universiti Teknologi Malaysia, 81310 UTM \\ Skudai, Malaysia. \\ ${ }^{2}$ Senior Lecturer, Faculty of Civil Engineering, Universiti Teknologi Malaysia, 81310 UTM Skudai, \\ Malaysia.
}

\begin{abstract}
Lightweight concrete (LWC) has been identified as an innovative technique for construction purposes. Lightweight concrete can be categorized into three different types which are no-fine aggregate concrete, lightweight aggregate concrete and aerated concrete. This paper studied the characteristic of the lightweight concrete in term of mechanical properties utilizing the palm oil clinker (POC) as lightweight aggregates. Two mixes of lightweight concrete were developed, namely as POCC100 and POCC50 where each mix utilized $100 \%$ and $50 \%$ of total replacement to fine and coarse aggregates, respectively. The fresh and hardened POC concrete was tested and compared to the normal concrete (NC). The hardened state of the concrete was investigated through density test, ultrasonic pulse velocity, cube compressive, splitting tensile, flexural, modulus of elasticity and Poisson's ratio. From density test results, POC falls into the category of lightweight concrete with a density of 1990.33 $\mathrm{kg} / \mathrm{m}^{3}$, which are below than normal weight concrete density. The mechanical properties test results on POCC100 and POCC50 showed that the concrete compressive strength was comparable about $85.70 \%$ and $96 \%$ compared to NC specimen, respectively. For the flexural strength, POCC50 and POCC100 were comparable about $98 \%$ and $97 \%$ to $\mathrm{NC}$ specimen, respectively. While splitting tensile strength of POCC50 and POCC100 was only $0.6 \%$ and $4 \%$ lower than NC specimen, respectively. In terms of sustainability of solid waste management, the application of the POC in construction will reduce the redundant of by-products resulted from the palm oil industries. After undergoing various testing of concrete mechanical properties, it can be concluded that POC aggregates was compatible to be used in ligtweight concrete mix proportion.
\end{abstract}

* Corresponding author: mznazreen@gmail.com 


\section{Introduction}

There are several guidelines to produce the lightweight concrete and one of them are by using the lightweight aggregates. The porous structure of the lightweight aggregates makes it low in specific gravity and bulk density compared to the normal crushed aggregates [1].

The mechanical properties of the concrete directly depend on the properties of the lightweight aggregates. Since the lightweight aggregates came from the various places and treatments, the physical properties of the lightweight aggregates must undergo several testing such as specific gravity, gradation, water absorption and void content to ensure whether the lightweight aggregates are suitable to use in the lightweight concrete mixture [2].

The constituent of the lightweight aggregates in the lightweight concrete mixture may have affected the strength of the concrete. Lightweight aggregates produce lower strength and elastic modulus compared to the mortar matrix, it indirectly depends on the mortar matrix to resist any imposed load on it [3]. Even though the strength of the concrete directly depends on the strength of the aggregates, it is still possible to produce a lightweight aggregates concrete with higher strength with the relevant mix design [4].

It is important to be noted that there are many advantages by applying the lightweight concrete in construction practices such as better heat insulation, sound absorption, increased seismic damping, and fire resistance [5] In term of structural beneficial, using the lightweight concrete will reduce the dead-load of the construction.

\section{Physical Properties of POC}

In this study, three types of concrete mix were prepared which is normal concrete (NC) and palm oil clinker concrete with 100\% (POCC100)and 50\% aggregates replacement (POCC50), respectively. Before the POC were used as fine and aggregates in the concrete mixture, physical properties of POC were investigated to ensure the suitability of POC to be utilized as aggregates and the comparison was made to the normal aggregates. The actual form of raw POC was shown in figure 1. Table 1 depicted the results of POC and normal aggregates physical properties.

Table 1. Physical properties of fine and coarse aggregates of POC, crushed granite and river sand

\begin{tabular}{|c|c|c|c|c|}
\hline \multirow{2}{*}{ Properties } & \multicolumn{2}{|c|}{ Coare } & \multicolumn{2}{c|}{ Fine } \\
\cline { 2 - 5 } & POC & $\begin{array}{c}\text { Crushed } \\
\text { granite }\end{array}$ & POC & $\begin{array}{c}\text { River } \\
\text { sand }\end{array}$ \\
\hline Specific gravity (SSD) & 1.92 & 2.65 & 1.98 & 2.60 \\
\hline $\begin{array}{c}\text { Loose Bulk Density } \\
\left(\mathrm{kg} / \mathrm{m}^{3}\right)\end{array}$ & 817 & 1294 & 918 & 1301 \\
\hline Moisture content (\%) & 1.30 & 0.28 & 1.27 & 0.8 \\
\hline Fineness modulus & 2.6 & 6 & 2.3 & 2.7 \\
\hline LA abrasion value (\%) & 38.70 & 38 & - & - \\
\hline
\end{tabular}




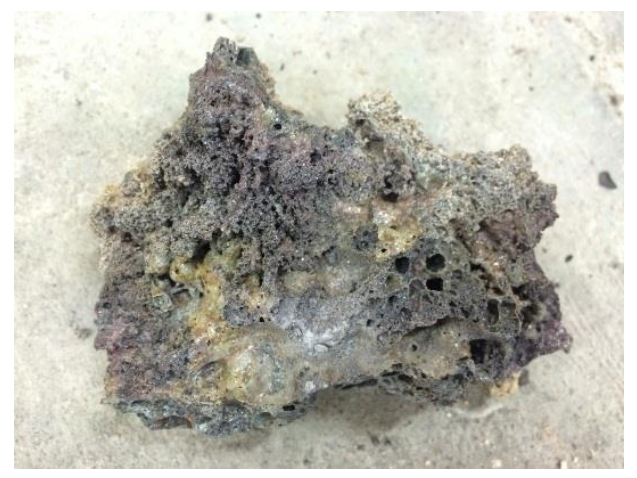

Fig. 1. Raw condition of POC

\section{Design mix proportion}

The lightweight aggregates concrete of palm oil clinker concrete (POCC) was designed in accordance with American Concrete Institute,[6]. while normal concrete (NC) was designed using Department of Environment (DOE) method [7]. All the mix was designed to achieved $30 \mathrm{MPa}$ at 28days of the curing process. All the mix proportion of NC, POCC50 and POCC100 were presented in Table 2.

Table 2. Concrete mix proportion $\left(\mathrm{kg} / \mathrm{m}^{3}\right)$

\begin{tabular}{|c|c|c|c|c|c|c|c|}
\hline $\begin{array}{c}\text { Types of } \\
\text { mix }\end{array}$ & $\begin{array}{c}\text { Cement } \\
(\mathrm{kg})\end{array}$ & $\begin{array}{c}\text { Water } \\
(\mathrm{kg})\end{array}$ & $\begin{array}{c}\text { SP } \\
(\mathrm{kg})\end{array}$ & $\begin{array}{c}\text { Sand } \\
(\mathrm{kg})\end{array}$ & $\begin{array}{c}\text { Crushed } \\
\text { granite } \\
(\mathrm{kg})\end{array}$ & $\begin{array}{c}\text { Fine } \\
\text { POC }(\mathrm{kg})\end{array}$ & Coarse POC $(\mathrm{kg})$ \\
\hline NC & 395 & 213.30 & - & 824.20 & 967.50 & - & - \\
\hline POCC50 & 500 & 210 & 0.5 & 301.86 & 150.93 & 301.86 & 150.93 \\
\hline POCC100 & 500 & 210 & 0.5 & - & - & 603.71 & 301.86 \\
\hline
\end{tabular}

\section{Mechanical properties of hardened concrete}

The mean properties of all mix specimens were compared to normal for the purpose of studying the concrete density, compressive strength, splitting tensile strength, flexural strength and modulus of elasticity.

\subsection{Concrete Density}

The result of the concrete density of NC, POCC50 and POCC100 specimens are shown in Figure 1 and Table 3, respectively. From the results, it is obviously shown that POCC50 and POCC100 have lower density compared to $\mathrm{NC}$ by $13 \%$ and $15 \%$, respectively. Whereas the difference density of POCC50 and POCC100 is too small, only $2 \%$. This is because of the composition of the aggregates and the density of the aggregates used in the concrete mixture. POCC can be classified as the lightweight aggregates since the cubic 
concrete density of the POCC100 is lower than $2000 \mathrm{~kg} / \mathrm{m}^{3}$ as stipulated by M.Hilton et al, 2007 [8] in the studies of structural lightweight aggregates having a density in the range of $1800-2000 \mathrm{~kg} / \mathrm{m}^{3}$.

Table 3. Density concrete of NC, POCC50 and POCC100

\begin{tabular}{|c|c|c|c|c|}
\hline $\begin{array}{c}\text { Types of } \\
\text { concrete }\end{array}$ & \multicolumn{3}{|c|}{ Density $\left(\mathrm{kg} / \mathrm{m}^{3}\right)$} & $\begin{array}{c}\text { Mean } \\
\left(\mathrm{kg} / \mathrm{m}^{3}\right)\end{array}$ \\
\hline NC & 2335 & 2345 & 2335 & 2338.33 \\
\hline POCC50 & 2031 & 2019 & 2026 & 2025.33 \\
\hline POCC100 & 1987 & 1990 & 1994 & 1990.33 \\
\hline
\end{tabular}

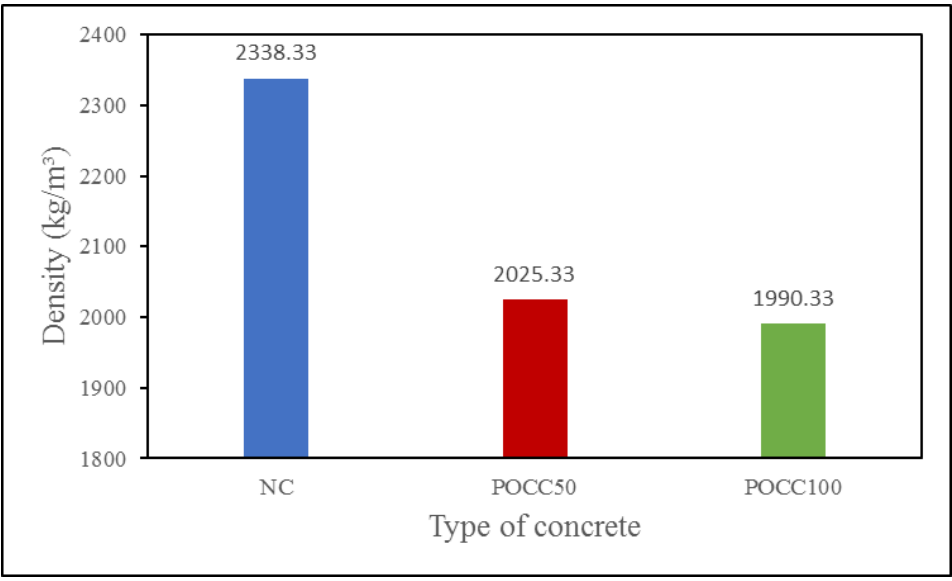

Fig. 2. Density of the hardened concrete

\subsection{Compressive strength}

Cube compressive test results as shown in Table 3 depicted that replacement of POC in the concrete mixture significantly affected the compressive strength of the concrete as compared with the NC specimens that were using crushed granite and river sand as coarse and fine aggregates. From the three type of concrete tested in this study revealed that concrete mix POCC100 containing $100 \%$ replacement crushed granite with the POC fine and coarse aggregates recorded the lowest cubic compressive strength at the ages 7,14 and 28 days consistently compared to NC and POCC50 specimens. The percentage difference is in range of $6.80 \%$ and $14.30 \%$ at all ages. Meanwhile, compressive strength test result for POCC50 was slightly lower compared to NC specimens in the range of $4.10 \%$ and $4.0 \%$ at all curing ages. It is clearly depicted that the cubic compressive strength decreased when the percentage replacement of the POC increasing. This is due to the reason that POC has lower aggregates crushing values. Kanadasan et al, 2014 [9] mentioned in the study that crushing value for POC was three times lower compared to normal aggregates due to the poor load-bearing capacity of the POC aggregates. However, the presence of such amount of the voids and pore on the POC physical structure could allow the cement paste to fill up the voids and pore area to create a sufficient concrete cubic compressive strength.

Table 4. Compressive strength of NC, POCC50 and POCC100 cube specimens 


\begin{tabular}{|c|c|c|c|}
\hline \multirow{2}{*}{$\begin{array}{c}\text { Types of } \\
\text { concrete }\end{array}$} & \multicolumn{3}{|c|}{ Mean $\left(\mathrm{N} / \mathrm{mm}^{2}\right)$} \\
\cline { 2 - 4 } & 7 days & 14days & 28days \\
\hline NC & 35.91 & 42.95 & 45.22 \\
\hline POCC50 & 34.44 & 41.46 & 43.43 \\
\hline POCC100 & 33.47 & 34.70 & 38.77 \\
\hline
\end{tabular}

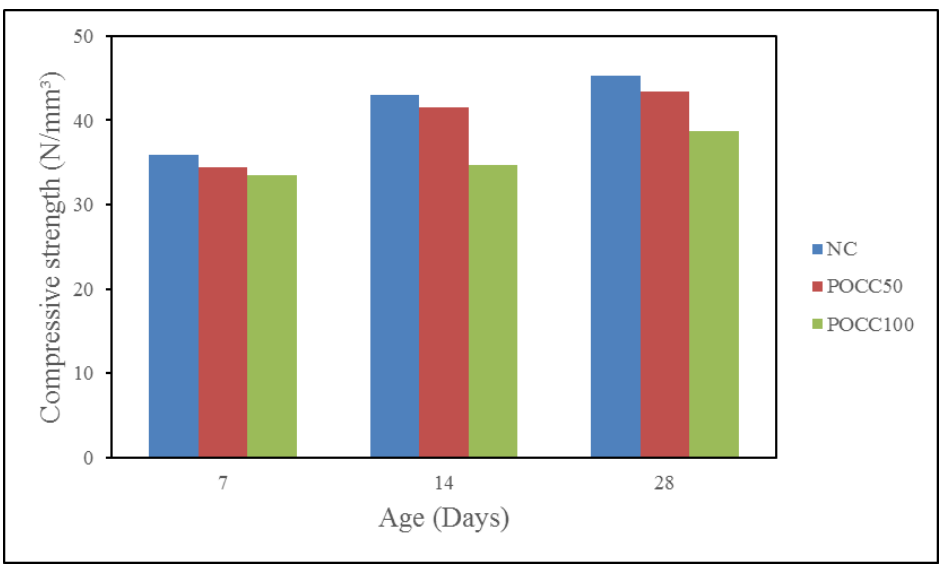

Fig. 3. Compressive strength of the hardened concrete specimens

\subsection{Splitting tensile strength}

Splitting tensile strength is closely related to the cracking when it comes to determination of cracking pattern and behaviour of the concrete. Table 6 and Figure 4 depicted the results of splitting tensile strength of NC, POCC50 and POCC100. The test result showed that splitting tensile strength for POCC100 are slightly lower by $3.60 \%$ and $3.0 \%$ difference compared to $\mathrm{NC}$ and POCC50, respectively. The relevance explanation regarding this phenomena was because of the existence of lightweight aggregates which is POC in the POCC100 specimen. The failure mode on the cylindrical concrete specimen containing POC showed the fracture path cut through the POC aggregates since the strength of the POC coarse aggregates has higher percentage loss of LA abrasion test as shown in Table 1. Mindess S and Young JF [10] stated that in their findings that existence of the lightweight aggregates (LWA) in the concrete proportion will reduce the strength of the concrete since LWA has lower strength compared to the mortar matrix.

Table 5. Splitting tensile strength of NC, POCC50 and POCC100 specimens

\begin{tabular}{|c|c|c|c|c|}
\hline $\begin{array}{c}\text { Types of } \\
\text { concrete }\end{array}$ & \multicolumn{3}{|c|}{$\begin{array}{c}\text { Splitting tensile strength } \\
\left(\mathrm{N} / \mathrm{mm}^{2}\right)\end{array}$} & $\begin{array}{c}\text { Mean } \\
\left(\mathrm{N} / \mathrm{mm}^{2}\right)\end{array}$ \\
\hline NC & 3.32 & 3.21 & 3.46 & 3.33 \\
\hline POCC50 & 3.27 & 3.19 & 3.48 & 3.31 \\
\hline POCC100 & 2.74 & 3.59 & 3.31 & 3.21 \\
\hline
\end{tabular}




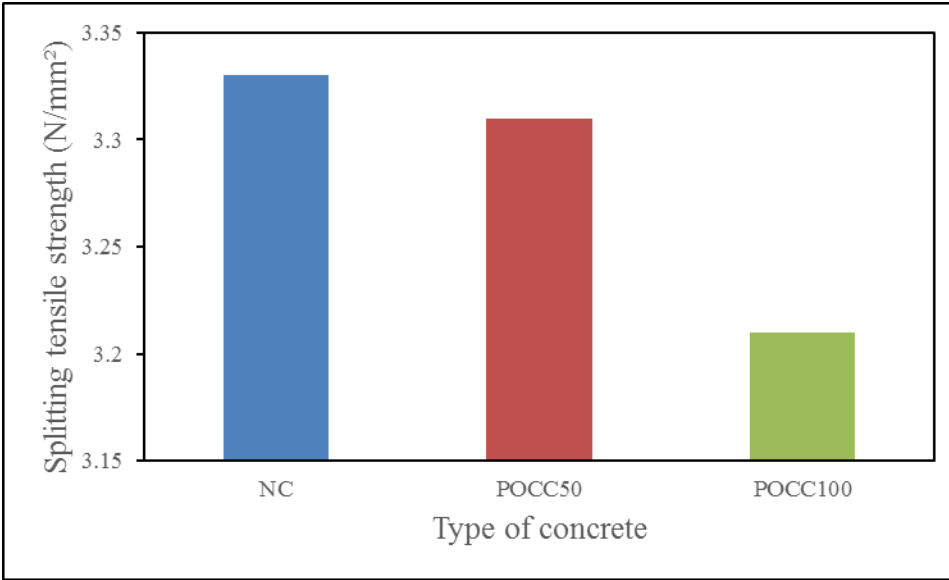

Fig. 4. Splitting tensile strength of hardened concrete specimens

\subsection{Flexural strength}

Flexural strength crucially depended on the performance of the compressive strength of the hardened state concrete [11]. Flexural strength test results at the age of 28days for NC, POCC50 and POCC100 specimens were presented in Table 7 and Figure 6. As illustrated in the table, the test result shows not much difference between the three specimens where the value of the flexural strength obtained was $2.02,1.99$ and $1.97 \mathrm{~N} / \mathrm{mm}^{2}$ for NC, POCC50 and POCC100 respectively. POCC50 and POCC100 registered only slight reduction strength by $1.5 \%$ and $2.5 \%$ compared to the NC specimen respectively. The main argument is due to the condition of POC which has higher porosity and void content in its physical structure as discussed in the sub-topic 4.2. The cellular structure of the POC let the air entrapped inside the concrete containing POC. Neville [12] has mentioned that inadequate curing process and air entrainment could affect the flexural strength of the concrete.

Table 6. Flexural strength of NC, POCC50 and POCC100 specimens

\begin{tabular}{|c|c|c|c|c|}
\hline $\begin{array}{c}\text { Types of } \\
\text { concrete }\end{array}$ & \multicolumn{3}{|c|}{$\begin{array}{c}\text { Flexural strength } \\
\left(\mathrm{N} / \mathrm{mm}^{2}\right)\end{array}$} & $\begin{array}{c}\text { Mean } \\
\left(\mathrm{N} / \mathrm{mm}^{2}\right)\end{array}$ \\
\hline NC & 2.14 & 2.01 & 1.91 & 2.02 \\
\hline POCC50 & 1.85 & 2.01 & 2.10 & 1.99 \\
\hline POCC100 & 2.05 & 1.95 & 1.91 & 1.97 \\
\hline
\end{tabular}




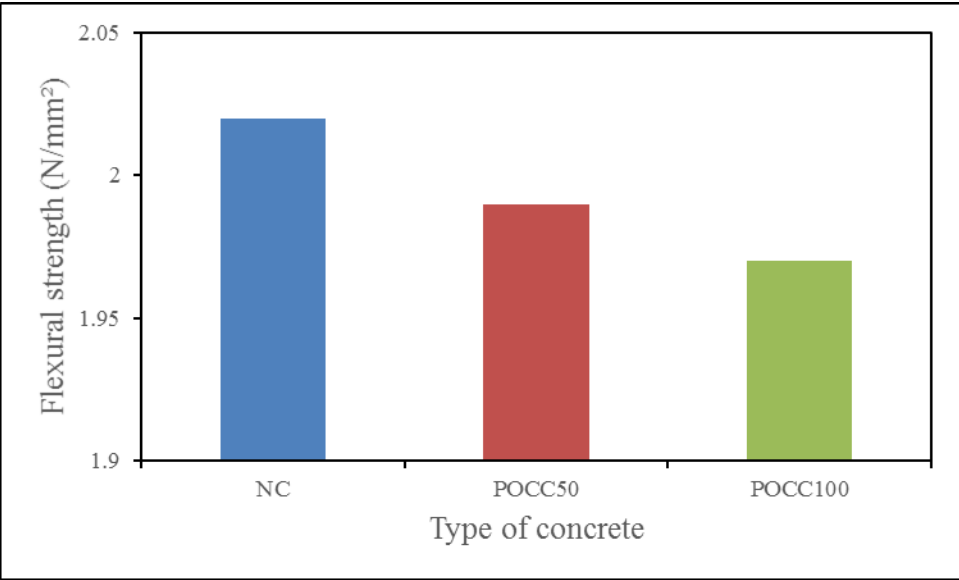

Fig. 5. Flexural strength of the hardened concrete specimens

\subsection{Modulus of elasticity (MOE)}

From the test result in Table 8, the elastic modulus value of the POCC100 was approximately $49 \%$ lower than the $\mathrm{NC}$ specimen. Although the percentage difference between E-value for POCC100 and NC was huge, this percentage is still in the acceptable range based on the suggestion by Neville and Brooks [13] that the E-value for lightweight aggregate concrete is commonly from $40 \%$ to $80 \%$ of normal or control concrete. On the other hands, POCC50 obtained the E-value $24.68 \mathrm{GPa}$ which is about $27 \%$ lower than NC. It is probably caused by the mix proportion of POCC50 was containing 50\% replacement of normal crushed granite and river sand with POC coarse and fine aggregates. For The Poisson's Ratio, $\mu$, the value of $\mu$ for POCC100 specimen has been observed to be highest at 0.20 followed by POCC50 with 0.18 . The NC specimen recorded the lowest Poisson's ratio value with 0.15 . The presence of POC in the concrete mix proportion allowed the concrete to elongate more it failed at the ultimate load. According to Neville and Brooks [13] the value of $\mu$ for both normal weight and lightweight concrete is in range of 0.15 to 0.20 . Thus, $\mu$ for all the specimens was acceptable.

Table 7. Modulus of elasticity and Poisson's ratio of hardened concrete

\begin{tabular}{|c|c|c|}
\hline $\begin{array}{c}\text { Types of } \\
\text { concrete }\end{array}$ & $\begin{array}{c}\text { Modulus of elasticity, } E \\
(\mathrm{GPa})\end{array}$ & Poisson's ratio, $\mu$ \\
\hline NC & 33.60 & 0.15 \\
\hline POCC50 & 24.68 & 0.18 \\
\hline POCC100 & 17.20 & 0.20 \\
\hline
\end{tabular}




\section{Conclusion}

The conclusion can be drawn from based on the present study :

i. Palm oil clinker was compatible to be utilized as lightweight aggregates in the lightweight concrete mix proportion. Palm oil clinker concrete (POCC) can be classified as a lightweight concrete.

ii. The replacement of the normal aggregates with POC aggregates could cause the reduction of compressive strength, flexural strength, splitting tensile strength and modulus elasticity of the concrete.

iii. The mechanical properties of POCC was comparable to normal weight concrete. Thus, POCC can be used in the structural purposes.

\section{References}

1. A.M. Neville., Hardened Concrete: Physical and Mechanical Aspects. ACI Monograph No. 6. (1971)

2. S. Chandra, L. Berntsson, Lightweight Aggregate Concrete: Science, Technology, and Applications, (2002)

3. MH. Zhang, Microstructure and properties of high strength lightweight concrete. Trondheim (Norway): Norwegian Institute of Technology. Division of Building Materials; (1989).

4. J. Newman, P. Owens, Properties of Lightweight Concrete, Advanced Concrete Technology Set, Butterworth-Heinemann, Oxford, pp. 3-29, (2003)

5. P. Shafigh, M.Z. Jumaat, H. Mahmud, Mix design and mechanical properties of oil palm shell lightweight aggregate concrete: a review. Int. J. Phys. Sci. 5 (14), $2127-$ 2134 (2010)

6. ACI Committee 211.2, Standard practice for selecting proportion for structural lightweight concrete. Detroit: American Concrete Institute, (1998)

7. Department of Environment (DOE), Concrete Mix Design, UK. (1988)

8. H. Ahmad, M. Hilton, N.M. Noor, Physical properties of local palm oil clinker and fly ash. In: Proceedings of 1st Engineering Conference on Energy and Environment (EnCon2007), Sarawak, Malaysia, UTHM Repository (2007)

9. J. Kanadasan, H.A. Razak, Mix design for self-compacting palm oil clinker concrete based on particle packing, Mater. Des. 56 (2014) 9-19

10. S. Mindess, J.F. Young, Concrete, Prentice Hall, Englewood Cliffs, NJ, (1981)

11. M. Aslam, P. Shafigh, M.Z. Jumaat, Oil-Palm by-products as lightweight aggregate in concrete mixture: a-review, 1-8 (2016)

12. A.M. Neville, Creep of Concrete, Plain, Reinforced, and Prestressed, North Holland Publishing Company, Amsterdam (1973)

13. A.M. Neville, J.J Brooks, Concrete Technology. Pearson Education Asia Pte Ltd., Printed in Malaysia, PP (CTP)(2008)

14. BS 1881: Part 121:Method for determination of static modulus of elasticity in compression, London (1983) 